\title{
Editorial: China: An emerging economic power, with a difference
}

\section{WENDY HARCOURT}

China is a new topic for Development, though as the articles indicate it is high time those of us working in development understand how China is emerging today as a new powerful economic player, but with a difference. The difference comes not only from the Maoist past and until recently the inward looking policy of China but also because of the sheer size of China. Both in economic and demographic terms China is a force to be reckoned with.

Development 50.3 on China can only begin to map out those dimensions from two somewhat obvious entry points. One set of articles examines development within China itself. They discuss the impact of the double-digit economic growth of the last three decades. They trace the changing rural and urban Chinese landscapes due to heavy investment in industrialization. They also point to the massive changes in the environment and peoples' livelihoods, coupled with the worrying deterioration of health and social welfare. The articles highlight the astounding level of economic growth but all ask at what cost to the majority of Chinese people and the environment? There is a measurable reduction of extreme poverty but in the push for economic growth China is not promoting quality growth and sustainable development. Indeed, who is benefiting from this economic growth? Is it the millions of poor workers in the Pearl River and Yangtze River Delta or the millions of consumers in the West profiting from the flood of cheap goods on their streets? Where do workers' rights fit in this picture? And how are Chinese officials dealing with increased social tensions and the beginnings of an environment movement? Is the use of Chinese women workers a competitive advantage or once again a double exploitation of women's taken-for-granted roles in the productive and caring economies? These are all disturbing questions that emerge from the first set of articles that look at development, information technologies, environment, labour conditions, gender and civil rights in China.

The second set of articles examine China's role in the world, in particular in Africa. These articles open up many questions around the role China is beginning to play as it engages with African states and companies in the search for resources and markets to keep up its remarkable level of growth. Here, a whole range of questions come into play. What are the 'petropolitics' China is playing in Sudan? Is this a new form of 
colonialism based on unchecked extraction of natural resources? Or is China an investor and ally in Africa? Another tricky question is that of human rights and democracy in relation to China itself and in its partnerships with African countries.

The entry of China into development poses some interesting questions for the transformation of the development discourse itself. What can those of us working and studying 'development' learn from China in order to change our work into a more global and inclusive field, taking into account Chinese realities. Conversely what can China learn from the critical thinking of development particularly around the exploitation of cultures, people and environment? Now that many people in the West are raising major concerns about the costs of development at least in its most exploitative capitalist forms what does the Chinese embrace of development 'with a difference' mean for our practice and discourse of development regionally and globally?

These are just some of the searching questions the journal asks from various perspectives.
International development policymakers and researchers working on China and environment, local activists engaged in civil rights, in particular women's workers rights in China, development project workers and African political commentators on development give us some of the latest thinking on China. They all bring a strong and clear message that we cannot judge China from a traditional economic development trajectory, nor can we place our assessment within a given (western) human rights or social justice perspective. China has its own unique historical, social and economic path that deserves to be understood far more widely in the West and far more carefully within international development. The economic power of China is beginning to be felt, within and outside of China. There is little in the history of development relations that allows us to forecast what will be the outcome. We hope though, even if as a first step, this journal issue helps us gain w>some insights into how many global economic, social and environmental dimensions will be shifting alongside the undoubted changes in Chinese internal and external policies in the future. 